\title{
Experimental Methodology used by Cell Cultures Laboratory from National Institute of Rehabilitation, Physical Medicine and Balneoclimatology, Bucharest, Romania to assess the therapeutic effect of natural factors
}

\author{
Constantin Munteanu ${ }^{1}$, Diana Munteanu
}

\section{Abstract}

The experimental study design on cell cultures allows the direct biological evaluation at the cellular level, of the therapeutic effect that natural factors can play over the organism.

Techniques for obtaining cell cultures requires a complex and laborious task that starts from live tissue sampling, continuous with isolation of cells and their preparation for sowing a culture plate.

This preparation involves mechanical and enzymatic action from the researcher on biological material.

Derived cell cultures are monitored morphologically by high-performance inverted biological microscope, with video camera for image acquisition.

In the final stage, the cells are scraped, and through biochemical and molecular techniques, the therapeutic efficiency hypothesis of the investigated natural factor is verified experimentally.

The cell cultures can be crioconservated in special containers with liquid nitrogen.

${ }^{1}$ Corresponding author: Constantin Munteanu, tel./fax: +40213186458, e-mail: constantin2378@yahoo.com,

Mailing address: B-dul Ion Mihalache, nr.11A, District 1, cod 79173, Bucharest, Romania,

http://www.cell-culture.xhost.ro/ 


\section{Cell Cultures Laboratory}

Periodical certification of natural factors quality used in therapeutic baths is an attribute of the National Institute of Rehabilitation, Physical Medicine and Balneoclimatology (INRMFB). Scientific arguments done by the research activity conducted at the institute, through the fundamental and applied research sector, will be to base for an evaluation of a resort and for promotion and motivation of that resort.

\section{Natural therapeutic factors}

The natural cure factors: mineral waters and thermo, salt lakes, mud and mofette, mines, climate, herbs, etc. are the fundamental condition, the starting point for designing and realizing any spa offers.

Primarily therapeutic minerals, with physicochemical properties that meet the needs of medical and preventive maintenance, enhancement, restoration to health, the work capacity and physical and mental comfort of the individual, represent spas resources.

\section{Experimental methodology}

Cell culture is the complex process by which cells are grown under controlled conditions. In practice, the term ,cell culture" has come to refer to the culturing of cells derived from multicellular eukaryotes, especially animal cells. However, there are also cultures of plants, fungi and microbes, including viruses, bacteria and protists. The historical development and methods of cell cultures are closely interrelated to those of tissue culture and organ culture.

Cultured mammalian cells are used extensively in cell biology studies. It requires a number of special skills in order to be able to preserve the structure, function, behavior, and biology of the cells in culture. This unit describes the basic skills required to maintain and preserve cell cultures: maintaining aseptic technique, preparing media with the appropriate characteristics, passaging, freezing and storage, recovering frozen stocks, and counting viable cells.

The cells are grown in an atmosphere of 5$10 \% \mathrm{CO}_{2}$ because the medium used is buffered with sodium bicarbonate/carbonic acid and the $\mathrm{pH}$ must be strictly maintained. Culture flasks should have loosened caps to allow for sufficient gas exchange. Cells should be left out of the incubator for as little time as possible and the incubator doors should not be opened for very long. The humidity must also be maintained for those cells growing in tissue culture dishes so a pan of water is kept filled at all times.

Cultures should be examined daily, observing the morphology, the color of the medium and the density of the cells. A tissue culture log should be maintained that is separate from your regular laboratory notebook. The log should contain: the name of the cell line, the medium components and any alterations to the standard medium, the dates on which the cells were split and/or fed, a calculation of the doubling time of the culture (this should be done at least once during the semester), and any observations relative to the morphology, etc.

On in vitro studies can be monitored: cell morphology, protein synthesis, secretion of certain substances, cellular metabolism, cells interaction through cellular receptors with different ligands, capture or release of electrolytes or other substances that enter the cellular environment.

The system of cell cultures defined the following categories: tissue culture, organ culture, adherent cell cultures and in suspension cultures, histiotype or organotype cultures, mass culture and clonal primary cultures, finite cell cultures, continuous cell lines.

Cells will initially go through a quiescent or lag phase that depends on the cell type, the seeding density, the media components, and previous handling. The cells will then go into exponential growth where they have the highest metabolic activity. The cells will then enter into stationary phase where the number of cells is constant; this is characteristic of a confluent population (where all growth surfaces are covered).

Response tracking and characterization of cells cultivated in vitro and subjected to direct action of natural therapeutic factors will be used for cell cultures obtained through the specific processes within the cell culture laboratories INRMFB.

Assessing changes in cellular and molecular level can be achieved by optical microscopy studies, which is tracked cell morphology, cell viability studies, immunohistochemistry studies, studies conducted by proteomic techniques, including electrophoresis and Western blotting, determination of biochemical parameters based on the culture medium, cell physiology studies, studies on cellular senescence, cell signaling studies.

Optical microscopy studies. After each experimental variant cells are fixed with $10 \%$ paraformaldehyde and stained with hematoxylineosine (for general histology). Microscopy studies allow the assessment of cellular morphology throughout the experimental period.

Immunohistochemistry studies. These studies will aim to assess changes in cell markers, stress proteins (HSP 70, HSP 90), pro-and antiapoptotic proteins (p53, Bax, Bcl-2, caspase 3 and cytochrome c) and the main matrix constituents (fibronectin, laminin, collagen). 
Institutul Național de Recuperare, Medicină Fizică şi Balneoclimatologie
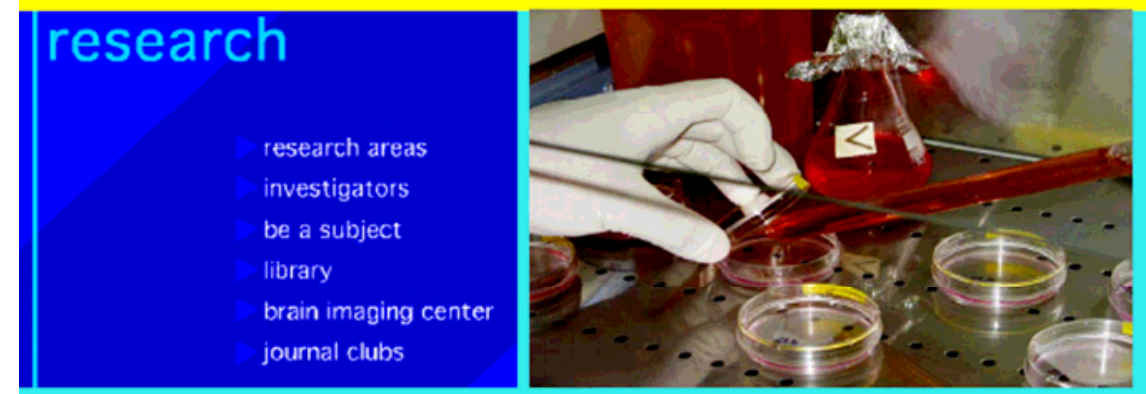

\section{Laborator Culturi Celulare}
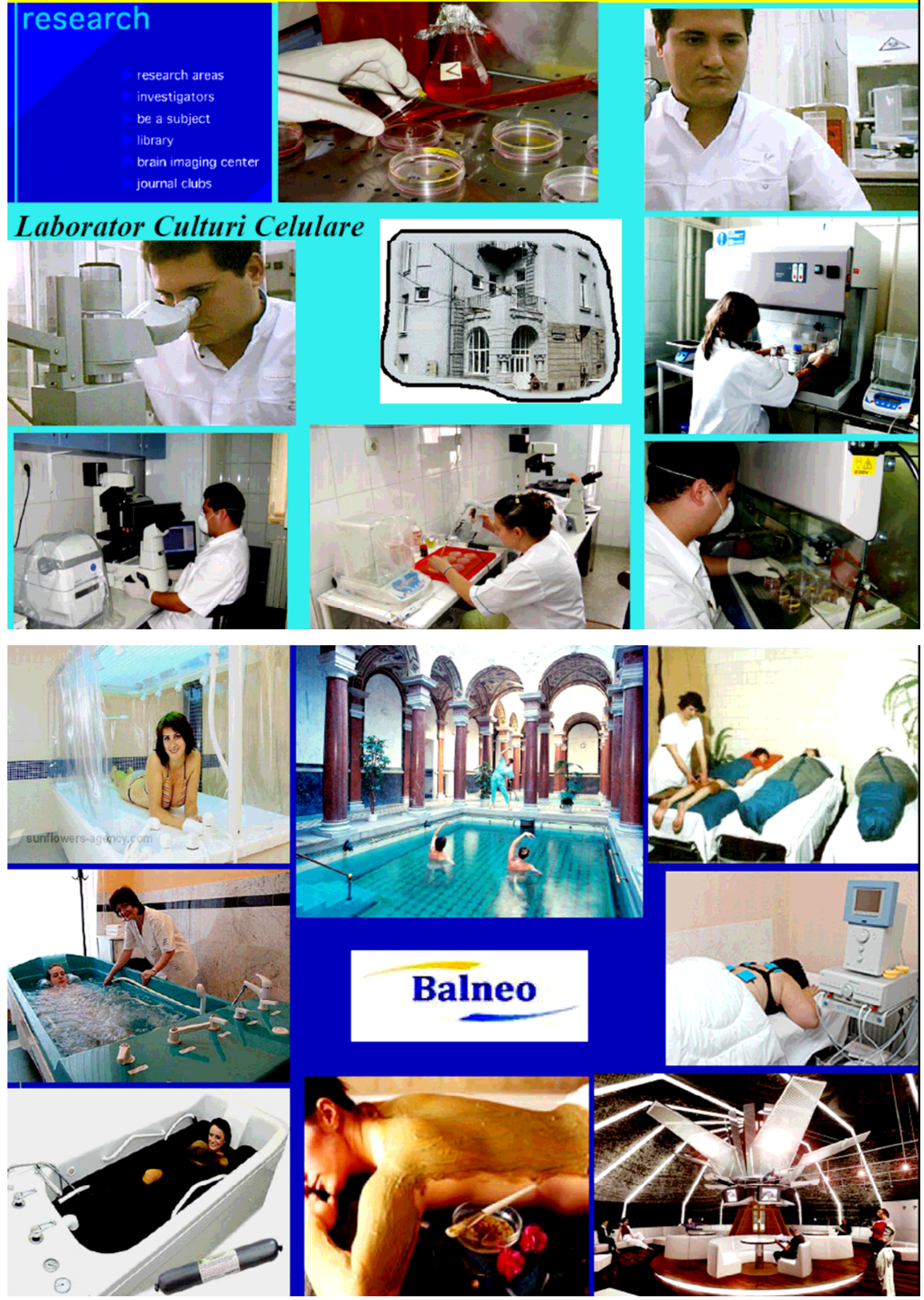

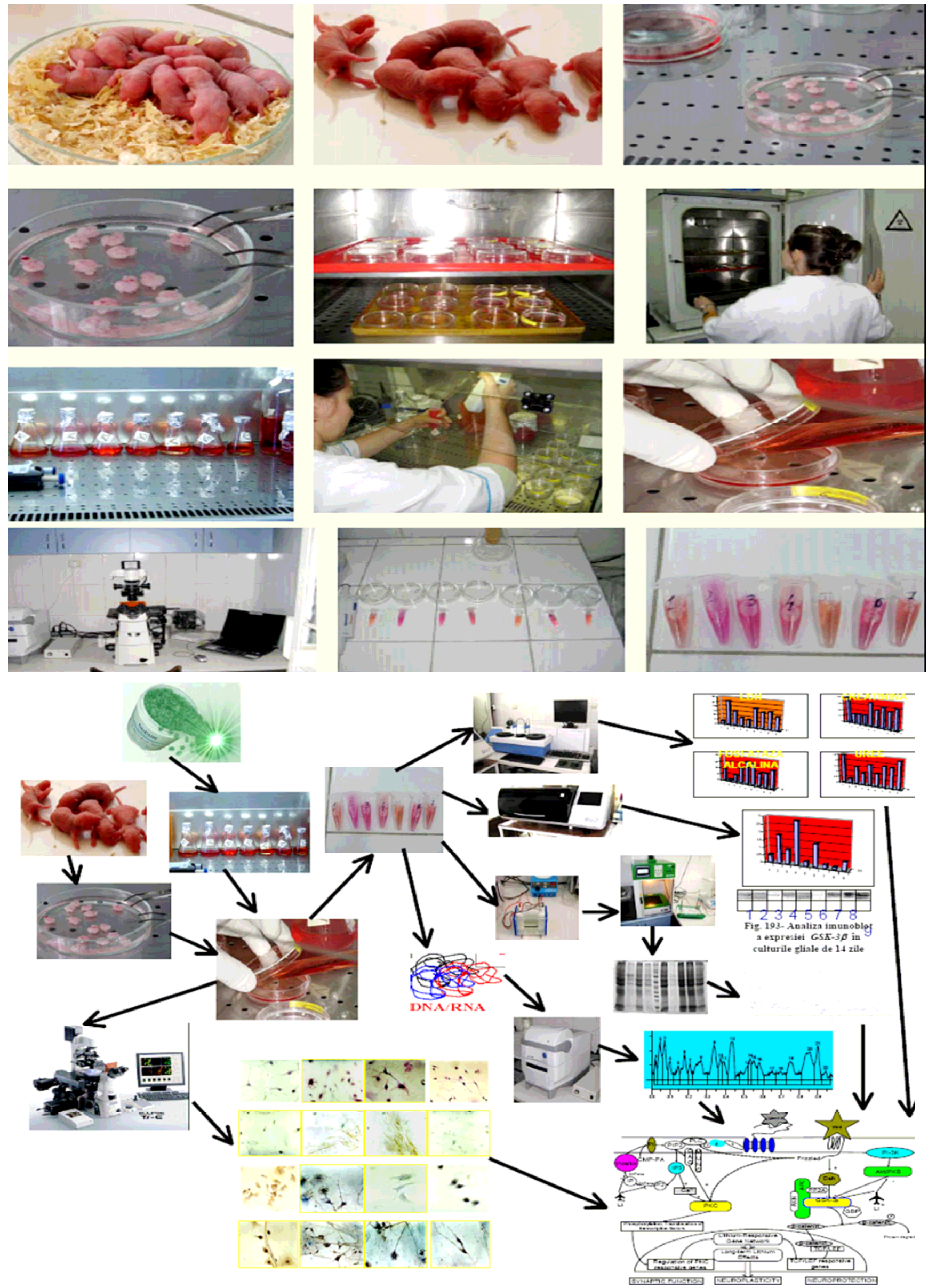

Experimental design for cell biology effects testing of natural therapeutic factors. 